\title{
Does intravascular ultrasound provide clinical benefits for percutaneous coronary intervention with bare-metal stent implantation? A meta-analysis of randomized controlled trials
}

\author{
Lucas Lodi-Junqueira ${ }^{1,2^{*}}$, Marcos Roberto de Sousa ${ }^{1,3}$, Leonardo Carvalho da Paixão ${ }^{1}$, Silvana Márcia Bruschi Kelles ${ }^{1}$,
} Carlos Faria Santos Amaral ${ }^{1,3}$ and Antonio L Ribeiro ${ }^{1,3}$

\begin{abstract}
Background: The role of intravascular ultrasound (IVUS) in percutaneous coronary interventions (PCI) is still controversial despite several previously published meta-analyses. A meta-analysis to evaluate the controversial role of IVUS-guided PCI with bare-metal stenting was performed and a previous published meta-analysis was re-evaluated in order to clarify the discrepancy between results of these studies.

Methods: A systematic review was performed by an electronic search of the PubMed, Embase and Web of Knowledge databases and by a manual search of reference lists for randomized controlled trials published until April 2011, with clinical outcomes and, at least, six months of clinical follow-up. A meta-analysis based on the intention to treat was performed with the selected studies.

Results: Five studies and 1,754 patients were included. There were no differences in death (OR=1.86; 95\% $\mathrm{Cl}=0.88-3.95 ; \mathrm{p}=0.10)$, non-fatal myocardial infarction $(\mathrm{OR}=0.65 ; 95 \% \mathrm{Cl}=0.27-1.58 ; \mathrm{p}=0.35)$ and major adverse cardiac events $(\mathrm{OR}=0.74 ; 95 \% \mathrm{Cl}=0.49-1.13 ; \mathrm{p}=0.16)$. An analysis of the previous published meta-analysis strongly suggested the presence of publication bias.
\end{abstract}

Conclusions: There is no evidence to recommend routine IVUS-guided PCI with bare-metal stent implantation. This may be explained by the paucity and heterogeneity of the studies published so far.

Keywords: Intravascular ultrasound, Meta-analysis, Publication bias, Bare-metal stent, Percutaneous coronary intervention, Coronary artery disease

\section{Background}

Since the first studies of intravascular ultrasound (IVUS) were published in 1989 [1-4], the technique has been widely used in clinical research and has contributed to technological improvements in interventional cardiology [5]. As a diagnostic tool, IVUS helps in the assessment of coronary lesions classified as moderate based on angiography, especially those located in the left main

\footnotetext{
* Correspondence: lucaslodi@yahoo.com.br

'Instituto de Avaliação de Tecnologias em Saúde (IATS), do Hospital das Clínicas da Universidade Federal de Minas Gerais (UFMG), Avenida Alfredo Balena, 110, CEP, 30130-100, Belo Horizonte, MG, Brazil

${ }^{2}$ Setor de Hemodinâmica do Hospital das Clínicas da UFMG, Avenida Alfredo Balena, 110, CEP, 30130-100, Belo Horizonte, MG, Brazil

Full list of author information is available at the end of the article
}

coronary artery [6,7], and in the assessment of long lesions, small artery lesions, bifurcations and in-stent restenosis $[8,9]$. As an ancillary technique in percutaneous coronary intervention (PCI), IVUS is useful in the evaluation of the target lesion and during stent implantation [10]. In theory, its use should reduce the risk of major adverse cardiovascular events (MACE) because of lower restenosis and stent thrombosis rates.

The first published systematic review evaluated the role of IVUS in PCI as well as its cost-effectiveness and did not show any difference between IVUS and angioguided PCI [11]. A few years later, a meta-analysis did not show any reduction in death or myocardial infarction (MI) but revealed reductions in repeat revascularization

\section{Biomed Central}

(c) 2012 Lodi-Junqueira et al.; licensee BioMed Central Ltd. This is an Open Access article distributed under the terms of the Creative Commons Attribution License (http://creativecommons.org/licenses/by/2.0), which permits unrestricted use, distribution, and reproduction in any medium, provided the original work is properly cited. 
and angiographic restenosis after a six-month follow-up [12]. This was corroborated by another meta-analysis that suggested an improvement in acute post-interventional results (larger minimal luminal diameter) and lower repeat revascularization, angiographic restenosis and MACE rates, but showed no effect on death or MI during the follow-up period of six to thirty months [13].

Since IVUS clinical benefit is still controversial and conclusions of meta-analyses may be misleading due to methodological issues, we performed a meta-analysis to assess the effect of IVUS in PCI with bare-metal stent implantation on clinically relevant outcomes, assessing the presence of publication bias. In addition, a critical review of the last published meta-analysis [13] was performed in order to clarify the discrepancy in the results found in this analysis comparing to medical literature.

\section{Methods}

The protocol for the present systematic review was based on the PRISMA Statement [14] and it was registered in the PROSPERO database (CRD42012002767).

\section{Strategy search}

We performed an electronic search of PubMed, Embase and Web of Knowledge databases with the following terms: Myocardial Ischemia; Ischemic Heart Disease; Acute Coronary Syndrome; Angina; Coronary Disease; Coronary Artery Disease; Coronary Occlusion; Coronary Thrombosis and Myocardial Infarction, in association with the terms Interventional Ultraso*; Intravascular Ultraso*; Intracoronary Ultraso*; IVUS and ICUS.

A manual search was also performed to retrieve potential articles cited in previous meta-analyses, in review articles and those considered to be relevant by the reviewers. The electronic search, which evaluated the articles included in the databases through April 2011, was limited neither by publication date nor by language.

\section{Eligibility criteria}

Only randomized controlled trials that compared IVUSguided PCI with angiography-guided PCI, with clinical outcomes, and at least six months of clinical follow-up, were included in quantitative synthesis. The clinical outcomes considered were death, nonfatal MI and the combined endpoint of MACE (death, nonfatal MI, or repeat revascularization). For repeat revascularization, a report of any new coronary revascularization (surgical or percutaneous) was considered, regardless of the lesion and of the vessel treated. Surrogate outcomes, such as angiographic outcomes, were not taken into account because these can show a positive result with no effect (or harmful effect) on clinical outcomes [15]. These clinical outcomes (death, nonfatal MI and MACE) were considered primary endpoints in our meta-analysis.

\section{Study selection}

The titles and abstracts from the articles retrieved by the search strategy had been independently evaluated by two reviewers (LCP, LLJ). All articles in which IVUS was mentioned were selected. These articles were fully read, and those that met the criteria were included. Disagreements were solved by consensus. If consensus was not achieved, a third reviewer (ALR) defined the question.

\section{Statistical analysis}

The intention-to-treat meta-analysis that followed the systematic review was performed by the random-effects model of the Comprehensive Meta-Analysis software (Borenstein M, Hedges L, Higgins J, Rothstein H. Version 2.2.048, Biostat, Englewood NJ, USA 2005), with the odds ratio (OR), 95\% confidence intervals and twosided $P$-values calculated for each outcome. The analysis of heterogeneity between studies was estimated by the $I^{2}$ statistic.

Publication bias evaluation was performed by Duval and Tweedie's Trim and Fill method [16]. Egger's test was also performed to analyze the impact of several factors on the size of the treatment effect [17]. The small study effect was also evaluated by cumulative analysis (from largest to smallest sample size) and by the onestudy-removed method.

\section{Results}

Literature search

A total of 4,247 articles in PubMed, 869 in Embase and 4,260 in Web of Knowledge databases were identified. Eight studies were selected according to the inclusion criteria (Figure 1) [18-26]. After a comprehensive analysis, three studies were excluded because they used a provisional stenting technique $[19,25,26]$, which is no longer performed because of its higher restenosis rate [27]. Table 1 summarizes the clinical and angiographic characteristics of the patients included in the selected studies.

\section{Qualitative study analysis}

There were significant differences between the five studies included in the final analysis (Table 2). One of the current indications of IVUS-guided PCI is for patients with long lesions (greater than 15 or $25 \mathrm{~mm}$ ) [8,28,29], who have been excluded from most studies [18,20,24]. Unlike the others, the TULIP study excluded those patients who had focal lesions (less than $20 \mathrm{~mm}$ in length). Every study but the AVID trial excluded patients with a current or past history of acute coronary syndrome (ACS). In the RESIST study, randomization was 


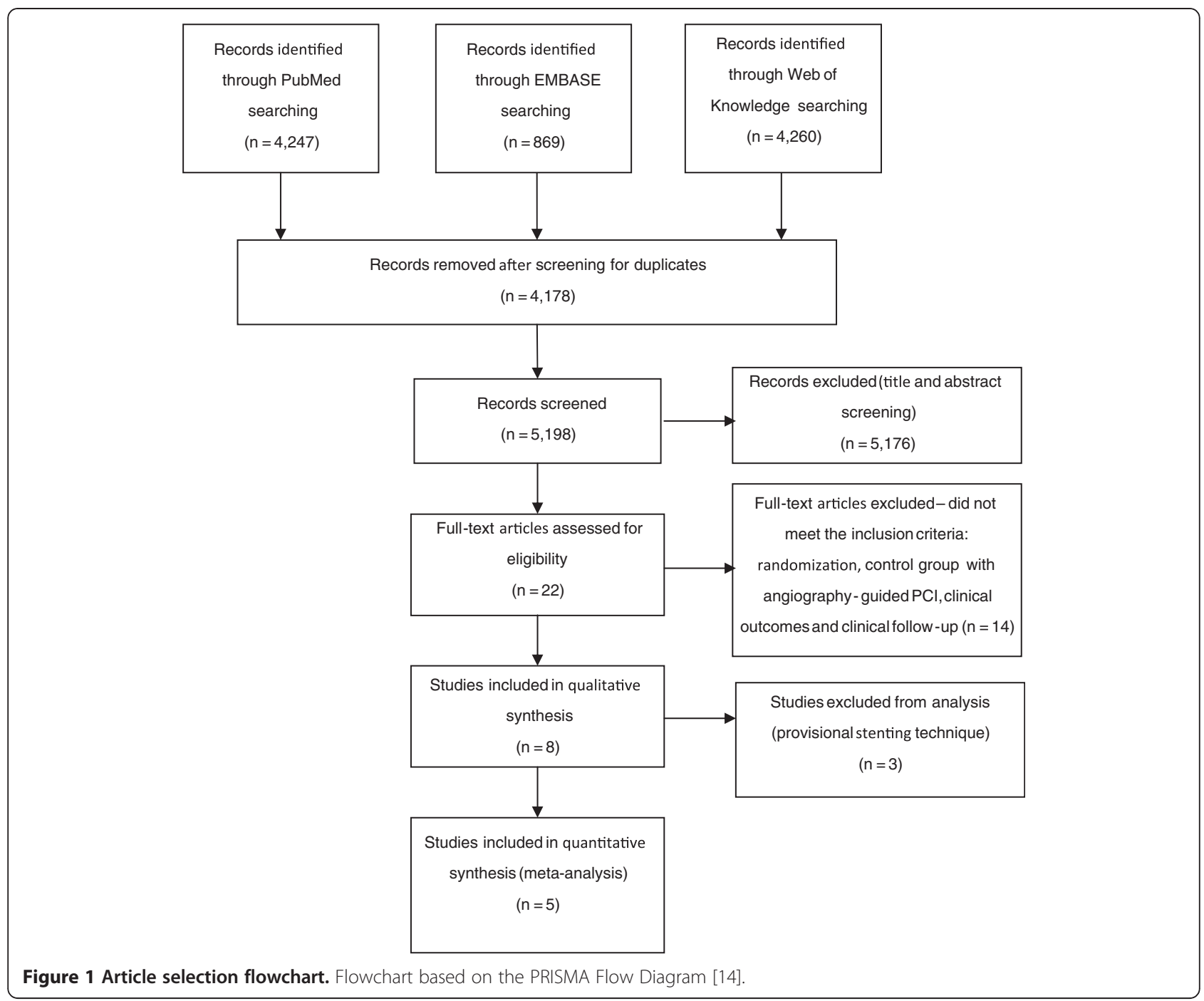

performed only after the intervention, which may have caused a selection bias. In the AVID trial, the IVUS analysis was only performed after implantation of the stent, excluding the initial assessment of the target lesion [8].

The criteria for optimal stent implantation were heterogeneous. Only the OPTICUS study used the criteria proposed by the MUSIC study [10]. The majority of patients underwent angiographic assessment after six months (angiographic follow-up) [20,22,24]. Another difference between the studies was in the criteria used for MACE. In the RESIST study, MI was not included. In the TULIP study, the MACE criteria included death, nonfatal MI and ischemia-driven target lesion revascularization (TLR). In the AVID trial, the composition of this outcome was not explained. In the other studies, the criteria for repeat revascularization were more comprehensive and included coronary artery bypass grafting (CABG) or a repeated PCI for any reason $[18,20,21,24]$.

\section{Heterogeneity}

The heterogeneity among the studies showed intermediate values in nonfatal MI $\left(I^{2}=48.82 \%\right)$ and MACE $\left(I^{2}=57.38 \%\right)$. For death, no heterogeneity was observed among the studies $\left(I^{2}=0 \%\right)$.

\section{Publication bias}

We also evaluated the possibility of publication bias (B0) for MACE. Egger's Test $(\mathrm{B} 0=-3.43$; $95 \% \mathrm{CI}-6.40$ to -0.47 , one-tailed $P$-value 0.02$)$ and the trim and fill test (observed OR 0.74, 95\% CI 0.49 to 1.13; two studies imputed: adjusted OR $0.93,95 \%$ CI 0.60 to 1.44 ) (Figure 2) were positive, suggesting the presence of small studies effects, which can be attributable to differences in design (not detected) or to publication bias.

\section{Meta-analysis results}

A total of 1,754 patients were randomized in five studies. There was no statistically significant difference between 
Table 1 Patient characteristics

\begin{tabular}{|c|c|c|c|c|c|c|c|c|c|c|}
\hline \multirow[t]{2}{*}{ Study } & \multicolumn{2}{|c|}{ DIPOL } & \multicolumn{2}{|c|}{ AVID } & \multicolumn{2}{|c|}{ RESIST } & \multicolumn{2}{|c|}{ TULIP } & \multicolumn{2}{|c|}{ OPTICUS } \\
\hline & IVUS & QCA & IVUS & QCA & IVUS & QCA & IVUS & QCA & IVUS & QCA \\
\hline \multicolumn{11}{|l|}{ Demographic characteristics } \\
\hline Patients, $\mathrm{n}$ & 83 & 80 & 369 & 375 & 79 & 76 & 73 & 71 & 273 & 275 \\
\hline Age. years, mean $\pm S D$ & $56 \pm 8$ & $54 \pm 8$ & $62 \pm 12$ & $63 \pm 11$ & $57 \pm 10$ & $56 \pm 12$ & $63 \pm 10$ & $61 \pm 10$ & $60.1 \pm 10$ & $61.5 \pm 9.5$ \\
\hline Men,\% & 71 & 73 & 73 & 68 & 86 & 93 & 71 & 72 & 77 & 78 \\
\hline Smoker,\% & 47 & 52 & - & - & 55 & 51 & 40 & 43 & 0.69 & 0.66 \\
\hline Previous Ml, $\%$ & 44 & 40 & 35 & 29 & 54 & 48 & - & - & 0.32 & 0.32 \\
\hline Previous CABG, $\%$ & - & - & 18 & 20 & - & - & - & - & 0.03 & 0.04 \\
\hline Previous PCl,\% & - & - & 24 & 25 & - & - & - & - & 0.2 & 0.2 \\
\hline Diabetes mellitus.\% & 10 & 11 & 15 & 17 & 9 & 8 & 21 & 16 & 0.17 & 0.17 \\
\hline Dyslipidemia,\% & 47 & 40 & 40 & 44 & 54 & 52 & 62 & 61 & 0.61 & 0.67 \\
\hline Hypertension,\% & - & - & 46 & 45 & 24 & 26 & 30 & 27 & 0.48 & 0.52 \\
\hline LV ejection fraction, $\%$, mean \pm SD & $52 \pm 9$ & $48 \pm 10$ & $53 \pm 13$ & $55 \pm 13$ & $51 \pm 9$ & $53 \pm 13$ & - & - & $56.5 \pm 14$ & $57.7 \pm 14.3$ \\
\hline \multicolumn{11}{|l|}{ Angiographic characteristics } \\
\hline \multicolumn{11}{|l|}{ Target vessel, $\%$} \\
\hline - Left anterior descending artery & 41 & 46 & 40 & 37 & 48 & 47 & 39 & 38 & 51 & 50 \\
\hline - Left circumflex artery & 26 & 24 & 15 & 18 & 11 & 11 & 10 & 21 & 18 & 14 \\
\hline - Right coronary artery & 33 & 30 & 35 & 32 & 41 & 42 & 51 & 41 & 30 & 35 \\
\hline - Left main coronary artery & - & - & 0.8 & 0.5 & - & - & - & - & - & - \\
\hline Lesion length, $\mathrm{mm}$, mean $\pm \mathrm{SD}$ & N/A & N/A & $13.0 \pm 7.7$ & $13.3 \pm 9.2$ & $7.7 \pm 3.5$ & $8.0 \pm 4.0$ & $27.0 \pm 9$ & $29.0 \pm 10$ & $11.9 \pm 5.1$ & $11.6 \pm 5.5$ \\
\hline Reference diameter, $\mathrm{mm}$, mean $\pm \mathrm{SD}$ & $3.21 \pm 0.64$ & $3.19 \pm 0.59$ & $3.05 \pm 0.64$ & $3.00 \pm 0.54$ & $3.0 \pm 0.64^{*}$ & $2.89 \pm 0.54^{*}$ & $2.95 \pm 0.57$ & $2.96 \pm 0.53$ & $2.97 \pm 0.53$ & $3.01 \pm 0.51$ \\
\hline Type B2 or C ACC/AHA lesions, $\%$ & 13 & 10 & $\mathrm{~N} / \mathrm{A}$ & $\mathrm{N} / \mathrm{A}$ & 43 & 48 & 100 & 100 & 76 & 78 \\
\hline \multicolumn{11}{|l|}{ Pre-intervention } \\
\hline - Minimum lumen diameter, $\mathrm{mm}$, mean $\pm \mathrm{SD}$ & $0.97 \pm 0.33$ & $0.95 \pm 0.32$ & $1.11 \pm 0.5$ & $1.09 \pm 0.47$ & $0.96 \pm 0.37$ & $1.02 \pm 0.44$ & $1.02 \pm 0.42$ & $0.99 \pm 0.41$ & $0.96 \pm 0.35$ & $0.99 \pm 0.34$ \\
\hline - Diameter stenosis, $\%$, mean \pm SD & $69.7 \pm 14.2$ & $70.2 \pm 11.4$ & $63.4 \pm 14.1$ & $63.5 \pm 14.3$ & $65.0 \pm 11.0$ & $64.0 \pm 12.0$ & $65.0 \pm 13.0$ & $65.0 \pm 10.0$ & $67.6 \pm 11.2$ & $66.7 \pm 10.1$ \\
\hline \multicolumn{11}{|l|}{ Post-intervention } \\
\hline - Minimum lumen diameter, $\mathrm{mm}$, mean $\pm \mathrm{SD}$ & $3.34 \pm 0.55$ & $3.06 \pm 0.52$ & $2.93 \pm 0.55$ & $2.87 \pm 0.48$ & $2.48 \pm 0.43$ & $2.46 \pm 0.46$ & $3.01 \pm 0.40$ & $2.80 \pm 0.31$ & $3.02 \pm 0.49$ & $2.91 \pm 0.41$ \\
\hline - Diameter stenosis, $\%$, mean \pm SD & $3.4 \pm 2.9$ & $8.9 \pm 5.4$ & N/A & N/A & $19.0 \pm 10.0$ & $19.0 \pm 9.0$ & $12.0 \pm 7.0$ & $13.0 \pm 9.0$ & $2.8 \pm 7.8$ & $6.0 \pm 8.0$ \\
\hline
\end{tabular}

* In the RESIST study, the reference diameter average was calculated. MI, myocardial infarction; CABG, coronary artery bypass graft; PCl, percutaneous coronary intervention; LV, left ventricular; ACA, American College

of Cardiology; AHA, American Heart Association; IVUS, intravascular ultrasound; N/A, not applicable, QCA, Quantitative Coronary Angiography. 
Table 2 Study characteristics

\begin{tabular}{|c|c|c|c|c|c|}
\hline Study & DIPOL & AVID & RESIST & TULIP & OPTICUS \\
\hline Enrolling years & 2000 to 2002 & 1995 to 1998 & 1995 to 1997 & 1991 to 2001 & 1996 to 1998 \\
\hline Randomized & Yes & Yes & Yes & Yes & Yes \\
\hline - Blinded? & Yes & Yes & N/A & N/A & Yes \\
\hline - When? & Pre-intervention & Pre-intervention & Post-intervention & Pre-intervention & Pre-intervention \\
\hline Intention-to-treat analysis & No & Yes & No & Yes & Yes \\
\hline \multicolumn{6}{|l|}{ Exclusion criteria } \\
\hline - Long lesions & Yes (> 25 mm) & No & Yes (> 15 mm) & No & Yes (> 25 mm) \\
\hline - Bifurcation & Yes & No & No & Yes & Yes \\
\hline - Left main coronary artery & Yes & Yes & No & No & Yes \\
\hline - Chronic total occlusion & Yes & Yes & Yes & Yes & No \\
\hline $\begin{array}{l}\text { - Recent acute coronary } \\
\text { syndrome }\end{array}$ & Yes & $\begin{array}{l}\text { No (except MI with } \\
\text { TIMI flow grade <3) }\end{array}$ & Yes & Yes & Yes \\
\hline - Small vessels & Yes $(\leq 2.75 \mathrm{~mm})$ & Yes $(<2.5 \mathrm{~mm})$ & Yes $(<3 \mathrm{~mm})$ & Yes $(<3 \mathrm{~mm})$ & Yes $(<2.5 \mathrm{~mm})$ \\
\hline - Others & $\begin{array}{l}\text { Age }<18 \text { and }>70 \text { y; } \\
\text { extensive calcification; } \\
\text { saphenous vein } \\
\text { graft lesions }\end{array}$ & $\begin{array}{l}\text { Age < } 18 \text { y; non-covered } \\
\text { dissection; large vessels } \\
(>3.25 \mathrm{~mm})\end{array}$ & Previous CABG & $\begin{array}{l}\text { Focal }(<20 \mathrm{~mm}) \\
\text { or ostial lesions }\end{array}$ & \\
\hline Pre-intervention IVUS & Yes & No & No & Yes & Yes \\
\hline Post-intervention IVUS & Yes & Yes & Yes & Yes & Yes \\
\hline PCl success criteria & $\begin{array}{l}\text { Stent CSA/average } \\
\text { CSA }>80 \% \text {, complete } \\
\text { apposition, stent } \\
\text { CSA }>7.5 \mathrm{~mm}^{2}\end{array}$ & $\begin{array}{l}\text { Stent CSA/distal } \\
\text { CSA }>90 \% \text {, complete } \\
\text { apposition, no dissection }\end{array}$ & $\begin{array}{l}\text { Stent CSA/average } \\
\text { CSA }>80 \%\end{array}$ & $\begin{array}{l}\text { Stent MLD/average } \\
\text { MLD }>80 \% \text {, complete } \\
\text { apposition, stent } \\
\text { CSA } \geq \text { distal CSA }\end{array}$ & $\begin{array}{l}\text { Stenosis }<10 \% \text { and } \\
\text { MUSIC study criteria }[10]\end{array}$ \\
\hline - PCl success by IVUS,\% & 96 & 63 & 61 & 89 & $\begin{array}{l}82.2 \text { and } \\
56 \text { (MUSIC) }\end{array}$ \\
\hline Clinical follow-up, months & 6 & 12 & 18 & 12 & 12 \\
\hline $\begin{array}{l}\text { Angiographic } \\
\text { follow-up, months }\end{array}$ & $6^{*}$ & & 6 (com USIC) & 6 & 6 \\
\hline MACE & $\begin{array}{l}\text { Death, nonfatal } \mathrm{Ml} \\
\text { repeat revascularization }\end{array}$ & Without explicit criteria & $\begin{array}{l}\text { Death, repeat } \\
\text { revascularization }^{\dagger}\end{array}$ & $\begin{array}{l}\text { Death, nonfatal MI, } \\
\text { clinical TLR }\end{array}$ & $\begin{array}{l}\text { Death, nonfatal } \mathrm{Ml} \\
\text { repeat revascularization }\end{array}$ \\
\hline
\end{tabular}

${ }^{*}$ Angiographic follow-up was left to the discretion of the operator: $87.9 \%$ (IVUS-guided group) and 83.7\% (angio-guided group). ${ }^{\dagger} \mathrm{CABG}$ or repeat PCI for any reason. IVUS, interventional ultrasound; $\mathrm{PCl}$, percutaneous coronary intervention; MACE, major adverse cardiovascular events; CSA, cross sectional area; MI, myocardial infarction; TIMI, thrombolysis in myocardial infarction; CABG, coronary artery bypass graft; MLD, minimum lumen diameter; clinical TLR, ischemia-driven target lesion revascularization.

the IVUS-guided group and the angiography-guided group (Table 3 ) for death (OR 1.86, 95\% CI 0.88 to 3.95, $P=0.10$ ) (Figure 3-A), nonfatal $\mathrm{MI}$ (OR 0.65, 95\% CI 0.27 to $1.58, P=0.35$ ) (Figure $3-\mathrm{B}$ ) or $\mathrm{MACE}$ (OR $0.74,95 \%$ CI 0.49 to $1.13, P=0.16$ ) (Figure $3-C$ ).

\section{Reviewing published data}

In order to clarify the discrepancy in MACE results found in this analysis compared to the medical literature, the data of a previously published meta-analysis [13] were re-evaluated (Figure 4). Among the studies selected by that meta-analysis, only two were not included in the present selection because the provisional stenting technique was employed in both of them $[19,25]$.

A funnel plot analysis was performed along with Egger's Test $(\mathrm{B} 0=-3.66,95 \% \mathrm{CI}-5.54$ to -1.78 , onetailed $P$-value $=0.002$ ) and the trim and fill test (observed OR 0.70, 95\% CI 0.50 to 0.98 ; three studies imputed: adjusted OR $0.89,95 \%$ CI 0.62 to 1.27 ), which suggested the presence of publication bias $[16,17]$.

A cumulative meta-analysis by reverse order of sample size was performed. The results only became positive when the last and smallest study was included in the analysis (Figure 5). Moreover, the one-study-removed analysis showed that the removal of any one of the smaller studies gave a neutral result from the meta-analysis (Figure 6). This makes it plausible to assume that one small unpublished study with negative results would be enough to nullify the effect of that meta-analysis.

\section{Discussion}

In this rigorously conducted meta-analysis of randomized controlled trials that compared IVUS-guided PCI with angiography-guided PCI using bare metal stents, 


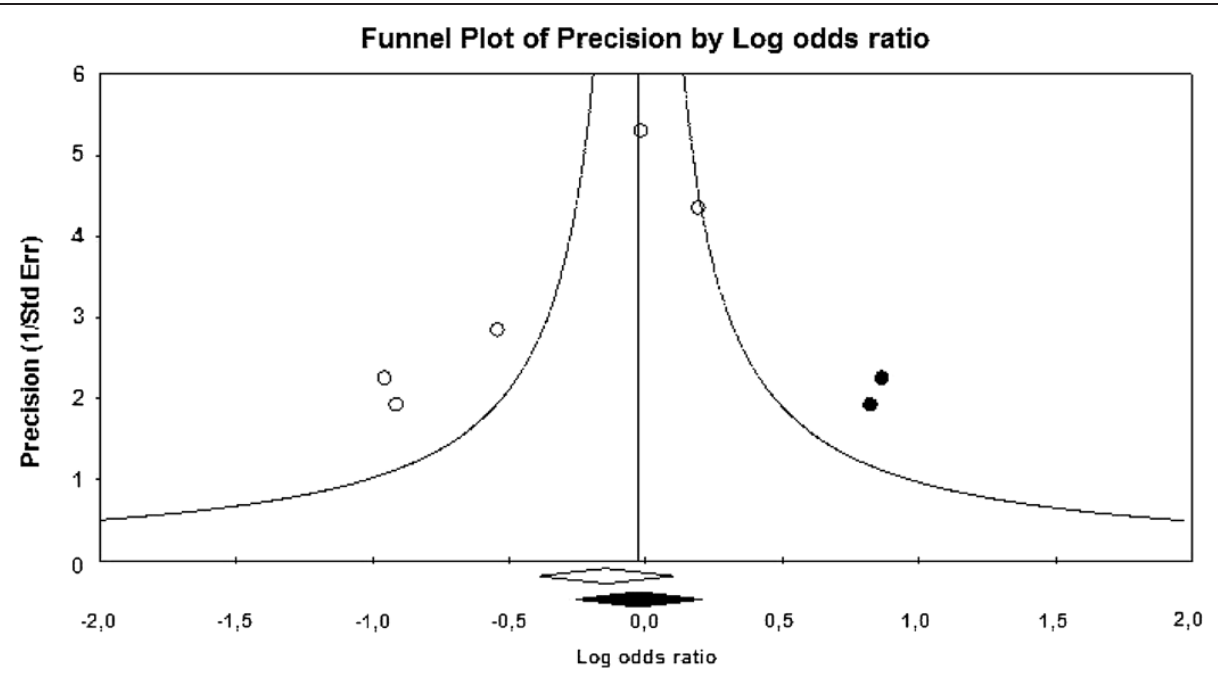

Figure 2 Duval and Tweedie's trim and fill test. The funnel plot shows the observed studies (white circles) and the imputed studies (black circles) in addition to the observed (white diamond) and adjusted combined effect (black diamond).

we did not find any advantage of the IVUS-guided strategy over the standard method in clinically relevant outcomes. Indeed, we found evidence of publication bias and of significant heterogeneity among the studies regarding the outcomes MI and MACE. These results diverge from the last two meta-analyses on this topic $[12,13]$, which included studies with provisional stenting, considered surrogate outcomes, and did not evaluate the presence of publication bias. However, they are in concordance with recently published studies of IVUSguided PCI with drug-eluting stent implantation, which were not associated with significant clinical benefits $[30,31]$.

\section{Differences between selected studies}

The five selected studies have important differences that might lead to completely different outcomes in another context. For example, the exclusion of patients presenting with ACS may have led to a reduction in postinterventional adverse events [32-35]. In the AVID trial, pre-interventional IVUS was not performed, which excluded an important phase of the method because one of the roles of IVUS is to assess the target lesion to help in the choice of technique and devices for the PCI [8]. Only the OPTICUS study used the MUSIC study criteria for optimal stent implantation [10], which theoretically could be associated with a lower MACE rate [36]. Angiographic follow-up was performed in most studies, which may have led to an overestimated rate of repeat revascularization, due to the oculo-stenotic reflex [37], which is the predisposition to indicate a PCI for any significant luminal obstruction, despite the presence or absence of myocardial ischemia [38]. The fact that most studies have used more comprehensive criteria for repeat revascularization may have also increased MACE rates $[18,20,24]$.

\section{Study biases}

The data analysis suggested the presence of publication bias in both meta-analyses. This bias may have led to apparently positive results that could be easily modified by unpublished studies with small sample sizes. It may be harmful because it can maintain or amplify an apparent beneficial effect of the intervention [39].

Significance-chasing bias is an enticing term that refers to the clustering of the most common types of meta-

Table 3 Clinical Outcomes

\begin{tabular}{lcccccccccccc}
\hline Study & \multicolumn{2}{c}{ DIPOL } & \multicolumn{2}{c}{ AVID } & \multicolumn{2}{c}{ RESIST } & \multicolumn{2}{c}{ TULIP } & \multicolumn{2}{c}{ OPTICUS } & Total \\
\hline & IVUS & QCA & IVUS & QCA & IVUS & QCA & IVUS & QCA & IVUS & QCA & IVUS & QCA \\
\hline Patients, $\mathrm{n}$ & 83 & 80 & 369 & 375 & 79 & 76 & 73 & 71 & 273 & 275 & 877 & 877 \\
\hline Death, $\mathrm{n}(\%)$ & $1(1.2)$ & $1(1.3)$ & $12(3.3)$ & $7(1.9)$ & $1(1.3)$ & $1(1.3)$ & $2(2.7)$ & $1(1.4)$ & $5(1.8)$ & $1(0.36)$ & $21(2.4)$ & $11(1.3)$ \\
\hline Nonfatal $\mathrm{Ml}, \mathrm{n}(\%)$ & $1(1.2)$ & $4(5)$ & $25(6.8)$ & $19(5.1)$ & $\mathrm{N} / \mathrm{A}$ & $\mathrm{N} / \mathrm{A}$ & $1(1.4)$ & $5(7.0)$ & $6(2.2)$ & $10(3.6)$ & $33(4.1)^{1}$ & $38(4.7)^{1}$ \\
\hline MACE, $\mathrm{n}(\%)$ & $6(7.2)$ & $13(16.2)$ & $68(18.4)$ & $70(18.7)$ & $20(25.3)$ & $28(36.8)$ & $9(12.3)$ & $19(26.8)$ & $49(17.9)$ & $42(15.3)$ & $152(17.3)$ & $172(19.6)$ \\
\hline
\end{tabular}

"The analysis of nonfatal MI excludes the RESIST Study, where this outcome was not calculated. MI, myocardial infarction; MACE, major adverse cardiovascular events; IVUS, interventional ultrasound. 


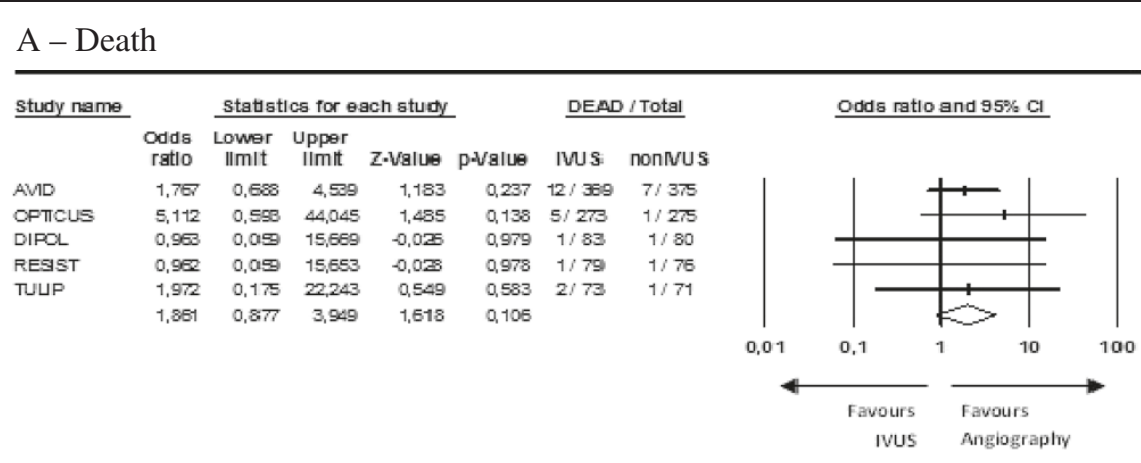

$\mathrm{B}-\mathrm{MI}$

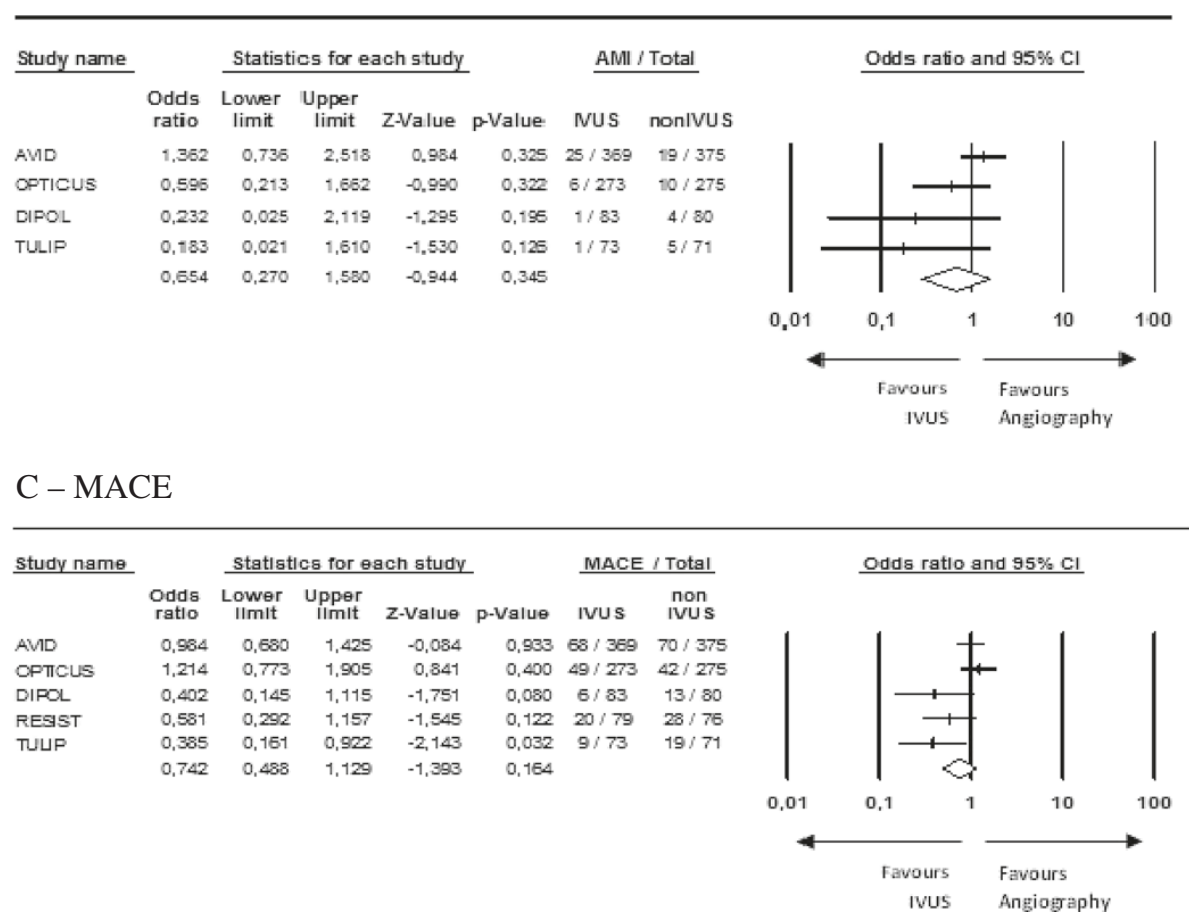

Figure 3 Meta-analysis by outcomes (random effects). (A) Death. (B) Myocardial infarction (MI). (C) Major adverse cardiovascular events (MACE).

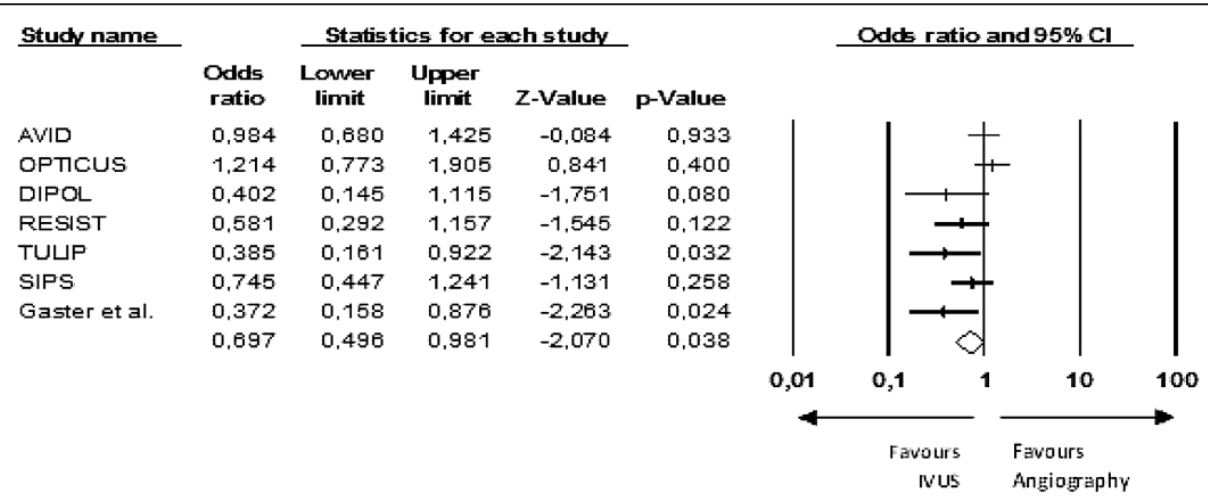

Figure 4 Original data from the re-evaluated meta-analysis - MACE [13]. 
analysis bias, including those in which the apparently negative results remain unpublished (study publication bias and selective outcome reporting bias), those in which negative results become positive (selective analysis reporting bias) and those in which no existing data are presented as positive (fabrication bias) [40,41].

Selective reporting bias is the most common problem in meta-analyses. In selective outcome reporting bias, specific data with a negative result are omitted from publication. In selective analysis reporting bias, which is even more frequent, a negative result calculated from a pre-determined analysis plan is replaced by a positive result achieved through post hoc data analysis [41].

Another major problem is the potential presence of interests other than scientific truth. This matter becomes critical when the object of the meta-analysis is an industry product, as in the present study, because most of the researches are conducted or funded by manufacturers (Table 4) $[42,43]$. There is a current trend towards opposing this practice [44].

Meta-analyses have gained prestige over time but they are still considered by some to be an ancillary method, accepted only when it corroborates the point of view of experts and of public policies [41]. They could play a fundamental role in changing (or in supporting) the evidence on relevant issues if conducted properly, with a pre-specified analysis plan and declared conflicts of interest for every study included, in addition to determining and reporting all possible biases.

\section{Limitations}

The paucity of randomized controlled trials comparing IVUS-guided PCI and angio-guided PCI and the exclusion of groups with specific lesions (long lesions, small vessels, bifurcations or left main coronary artery) may have masked a possible benefit. The same point applies to the exclusion of patients presenting with ACS, whose rate of cardiovascular events is higher, and PCI, when indicated, may even reduce mortality [32-34].

The low statistical power of the present study and of the re-evaluated meta-analysis [13] is due to the presence of heterogeneity and to the possibility of study publication bias. The presence of other biases might be possible but that is even more difficult to prove.

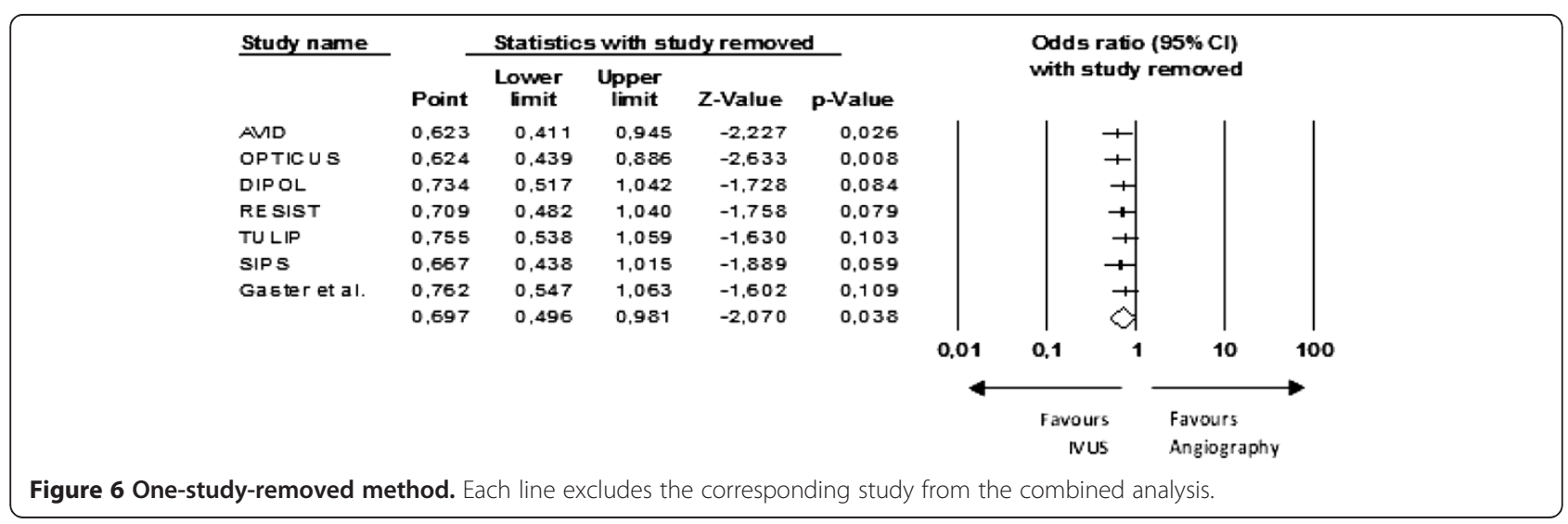


Table 4 Study funding and conflicts of interest of the authors of original articles included in this meta-analysis

\begin{tabular}{lcc}
\hline \multicolumn{1}{c}{ Trial } & Industry funding & Conflicts of interest (authors) \\
\hline DIPOL & None declared & N/A \\
\hline AVID & None declared & $\begin{array}{r}\text { Accumetrics; Baxter; BDS; Boston } \\
\text { Scientific; Cardium; Conor Medical; } \\
\text { Cordis; Johnson \& Johnson; } \\
\text { Medtronic; Volcano }\end{array}$ \\
\hline RESIST & None declared & N/A \\
\hline TULIP & Medtronic; AVE & Boston Scientific; Guidant \\
\hline OPTICUS & $\begin{array}{c}\text { Boston Scientific; } \\
\text { Johnson \& Johnson }\end{array}$ & N/A \\
\hline
\end{tabular}

$\mathrm{N} / \mathrm{A}$, not applicable.

\section{Conclusion}

The clinical benefit of IVUS-guided PCI with bare-metal stent implantation could be determined neither by the meta-analysis presented in this study nor by the reevaluated meta-analysis. This may be explained by the paucity and heterogeneity of the studies published so far. Furthermore, both meta-analyses showed possible publication biases.

Therefore, there is no evidence so far to recommend routine IVUS-guided PCI with bare-metal stent implantation. Studies on specific subgroups and performance of a simple large randomized trial could show different results.

This research was conducted by public funding from the National Council for Scientific and Technological Development (CNPq) (CNPq Project: 559584/2009-1).

\section{Competing interest}

The authors declare no conflicts of interest in the preparation and in the presentation of this meta-analysis.

\section{Authors' contributions \\ $L L J$ participated in the design of the study, retrieved, reviewed and selected the articles from electronic and manual searches, helped to discuss the results and to draft the manuscript. MRS participated in the design of the study, performed the statistical analysis and helped to discuss the results and to draft the manuscript. LCP retrieved, reviewed and selected the articles from electronic and manual searches. SMBK participated in the design of the study and helped to retrieve articles from electronic searches, to discuss the results and to draft the manuscript. CFSA participated in the design of the study and helped to discuss the results and to draft the manuscript. ALR participated in the coordination of the study, helped to select the articles, to discuss the results and to draft the manuscript. All authors read and approved the final manuscript.}

\footnotetext{
Author details

'Instituto de Avaliação de Tecnologias em Saúde (IATS), do Hospital das Clínicas da Universidade Federal de Minas Gerais (UFMG), Avenida Alfredo Balena, 110, CEP, 30130-100, Belo Horizonte, MG, Brazil. ${ }^{2}$ Setor de Hemodinâmica do Hospital das Clínicas da UFMG, Avenida Alfredo Balena, 110, CEP, 30130-100, Belo Horizonte, MG, Brazil. ${ }^{3}$ Departamento de Clínica Médica da Faculdade de Medicina da UFMG, Avenida Alfredo Balena, 190, CEP, 30130-100, Belo Horizonte, MG, Brazil.
}

Received: 20 June 2012 Accepted: 10 September 2012 Published: 21 September 2012

\section{References}

1. Yock PG, Linker DT, Angelsen BA: Two-dimensional intravascular ultrasound: technical development and initial clinical experience. J Am Soc Echocardiogr 1989, 2:296-304.

2. Gussenhoven WJ, Essed CE, Frietman P, Mastik F, Lancee C, Slager C, Serruys P, Gerritsen P, Pieterman H, Bom N: Intravascular echographic assessment of vessel wall characteristics: a correlation with histology. Int J Card Imaging 1989, 4:105-116.

3. Hodgson JM, Graham SP, Savakus AD, Dame SG, Stephens DN, Dhillon PS, Brands D, Sheehan H, Eberle MJ: Clinical percutaneous imaging of coronary anatomy using an over-the-wire ultrasound catheter system. Int J Card Imaging 1989, 4:187-193.

4. Roelandt JR, Serruys PW, Bom N, Gussenhoven WG, Lancee CT, Ten HH: Intravascular real-time, two-dimensional echocardiography. Int J Card Imaging 1989, 4:63-67.

5. Colombo A, Hall P, Nakamura S, Almagor Y, Maiello L, Martini G, Gaglione A, Goldberg SL, Tobis JM: Intracoronary stenting without anticoagulation accomplished with intravascular ultrasound guidance. Circulation 1995, 91:1676-1688

6. Abizaid AS, Mintz GS, Abizaid A, Mehran R, Lansky AJ, Pichard AD, Satler LF, Wu H, Kent KM, Leon MB: One-year follow-up after intravascular ultrasound assessment of moderate left main coronary artery disease in patients with ambiguous angiograms. J Am Coll Cardiol 1999, 34:707-715

7. Abizaid AS, Mintz GS, Mehran R, Abizaid A, Lansky AJ, Pichard AD, Satler LF, Wu H, Pappas C, Kent KM, Leon MB: Long-term follow-up after percutaneous transluminal coronary angioplasty was not performed based on intravascular ultrasound findings: importance of lumen dimensions. Circulation 1999, 100:256-261.

8. Bourantas CV, Naka KK, Garg S, Thackray S, Papadopoulos D, Alamgir FM Hoye A, Michalis LK: Clinical indications for intravascular ultrasound imaging. Echocardiography 2010, 27:1282-1290.

9. Orford JL, Denktas AE, Williams BA, Fasseas P, Willerson JT, Berger PB, Holmes DR Jr, PRESTO Investigators: Routine intravascular ultrasound scanning guidance of coronary stenting is not associated with improved clinical outcomes. Am Heart J 2004, 148:501-506.

10. De JP, Mudra H, Figulla H, Almagor Y, Doucet S, Penn I, Colombo A, Hamm C, Bartorelli A, Rothman M, Nobuyoshi M, Yamaguchi T, Voudris V, DiMario C, Makovski S, Hausmann D, Rowe S, Rabinovich S, Sunamura M, van Es GA: Intravascular ultrasound-guided optimized stent deployment. Immediate and 6 months clinical and angiographic results from the Multicenter Ultrasound Stenting in Coronaries Study (MUSIC Study). Eur Heart J 1998, 19:1214-1223

11. Berry E, Kelly S, Hutton J, Lindsay HS, Blaxill JM, Evans JA, Connelly J, Tisch J, Walker GC, Sivananthan UM, Smith MA: Intravascular ultrasound-guided interventions in coronary artery disease: a systematic literature review, with decision-analytic modelling, of outcomes and cost-effectiveness. Health Technol Assess 2000, 4:1-117.

12. Casella G, Klauss V, Ottani F, Siebert U, Sangiorgio P, Bracchetti D: Impact of intravascular ultrasound-guided stenting on long-term clinical outcome: a meta-analysis of available studies comparing intravascular ultrasound-guided and angiographically guided stenting. Catheter Cardiovasc Interv 2003, 59:314-321.

13. Parise H, Maehara A, Stone GW, Leon MB, Mintz GS: Meta-analysis of randomized studies comparing intravascular ultrasound versus angiographic guidance of percutaneous coronary intervention in predrug-eluting stent era. Am J Cardiol 2011, 107:374-382.

14. Moher D, Liberati A, Tetzlaff J, Altman DG: Preferred reporting items for systematic reviews and meta-analyses: the PRISMA statement. BMJ 2009, 339:b2535.

15. la Cour JL, Brok J, Gotzsche PC: Inconsistent reporting of surrogate outcomes in randomised clinical trials: cohort study. BMJ 2010, 341:c3653.

16. Sutton AJ, Duval SJ, Tweedie RL, Abrams KR, Jones DR: Empirical assessment of effect of publication bias on meta-analyses. BMJ 2000, 320:1574-1577.

17. Egger M, Smith GD: Bias in location and selection of studies. BMJ 1998, 316:61-66.

18. Investigators of Direct Stenting vs Optimal Angioplasty Trial (DIPOL), Gil RJ, Pawlowski T, Dudek D, Horszczaruk G, Zmudka K, Lesiak M, Witkowski A, Ochała A, Kubica J: Comparison of angiographically guided direct stenting technique with direct stenting and optimal balloon angioplasty 
guided with intravascular ultrasound. The multicenter, randomized trial results. Am Heart J 2007, 154:669-675.

19. Gaster AL, Slothuus SU, Larsen J, Korsholm L, Von BC, Jensen S, Thayssen P, Pedersen KE, Haghfelt TH: Continued improvement of clinical outcome and cost effectiveness following intravascular ultrasound guided PCl: insights from a prospective, randomised study. Heart 2003, 89:1043-1049.

20. Schiele F, Meneveau N, Vuillemenot A, Zhang DD, Gupta S, Mercier M, Danchin N, Bertrand B, Bassand JP: Impact of intravascular ultrasound guidance in stent deployment on 6-month restenosis rate: a multicenter, randomized study comparing two strategies-with and without intravascular ultrasound guidance. RESIST Study Group. REStenosis after Ivus guided STenting. J Am Coll Cardiol 1998, 32:320-328.

21. Schiele F, Meneveau N, Seronde MF, Caulfield F, Pisa B, Arveux P, Danchin $\mathrm{N}$, Bassand JP: Medical costs of intravascular ultrasound optimization of stent deployment. Results of the multicenter randomized 'REStenosis after Intravascular ultrasound STenting' (RESIST) study. Int J Cardiovasc Intervent 2000, 3:207-213

22. Oemrawsingh PV, Mintz GS, Schalij MJ, Zwinderman AH, Jukema JW, van der Wall EE: Intravascular ultrasound guidance improves angiographic and clinical outcome of stent implantation for long coronary artery stenoses: final results of a randomized comparison with angiographic guidance (TULIP Study). Circulation 2003, 107:62-67.

23. Russo RJ, Silva PD, Teirstein PS, Attubato MJ, Davidson CJ, DeFranco AC, Fitzgerald PJ, Goldberg SL, Hermiller JB, Leon MB, Ling FS, Lucisano JE, Schatz RA, Wong SC, Weissman NJ, Zientek DM, AVID Investigators: A randomized controlled trial of angiography versus intravascular ultrasound-directed bare-metal coronary stent placement (the AVID Trial). Circ Cardiovasc Interv 2009, 2:113-123.

24. OPTICUS (OPTimization with ICUS to reduce stent restenosis) Study Investigators, Mudra H, Di MC, De JP, Figulla HR, Macaya C, Zahn R, Wennerblom B, Rutsch W, Voudris V, Regar E, Henneke KH, Schächinger V, Zeiher A: Randomized comparison of coronary stent implantation under ultrasound or angiographic guidance to reduce stent restenosis (OPTICUS Study). Circulation 2001, 104:1343-1349.

25. Frey AW, Hodgson JM, Muller C, Bestehorn HP, Roskamm H: Ultrasound-guided strategy for provisional stenting with focal balloon combination catheter: results from the randomized Strategy for Intracoronary Ultrasound-guided PTCA and Stenting (SIPS) trial. Circulation 2000, 102:2497-2502.

26. Mueller C, Hodgson JM, Schindler C, Perruchoud AP, Roskamm H, Buettner $\mathrm{HJ}$ : Cost-effectiveness of intracoronary ultrasound for percutaneous coronary interventions. Am J Cardiol 2003, 91:143-147.

27. Al SJ, Holmes DR Jr, Salam AM, Lennon R, Berger PB: Impact of coronary artery stents on mortality and nonfatal myocardial infarction: metaanalysis of randomized trials comparing a strategy of routine stenting with that of balloon angioplasty. Am Heart J 2004, 147:815-822.

28. Colombo A, De GJ, Moussa I, Kobayashi Y, Karvouni E, Di MC, Di Mario C, Albiero R, Finci L, Moses J: Intravascular ultrasound-guided percutaneous transluminal coronary angioplasty with provisional spot stenting for treatment of long coronary lesions. J Am Coll Cardiol 2001, 38:1427-1433.

29. Orford JL, Lerman A, Holmes DR: Routine intravascular ultrasound guidance of percutaneous coronary intervention: a critical reappraisal. J Am Coll Cardiol 2004, 43:1335-1342.

30. Biondi-Zoccai G, Sheiban I, Romagnoli E, De SS, Tamburino C, Colombo A, Burzotta F, Presbitero P, Bolognese L, Paloscia L, Rubino P, Sardella G, Briguori C, Niccoli L, Franco G, Di Girolamo D, Piatti L, Greco C, Capodanno $D$, Sangiorgi G: Is intravascular ultrasound beneficial for percutaneous coronary intervention of bifurcation lesions? Evidence from a 4,314patient registry. Clin Res Cardiol 2011, 100:1021-1028.

31. Jakabcin J, Spacek R, Bystron M, Kvasnak M, Jager J, Veselka J, Kala P, Cervinka P: Long-term health outcome and mortality evaluation after invasive coronary treatment using drug eluting stents with or without the IVUS guidance. Randomized control trial. HOME DES IVUS. Catheter Cardiovasc Interv 2010, 75:578-583.

32. Lagerqvist B, Husted S, Kontny F, Stahle E, Swahn E, Wallentin L: 5-year outcomes in the FRISC-II randomised trial of an invasive versus a non-invasive strategy in non-ST-elevation acute coronary syndrome: a follow-up study. Lancet 2006, 368:998-1004

33. Randomized Intervention Trial of unstable Angina Investigators, Fox KA, Poole-Wilson PA, Henderson RA, Clayton TC, Chamberlain DA, Shaw TR, Wheatley DJ, Pocock SJ: Interventional versus conservative treatment for patients with unstable angina or non-ST-elevation myocardial infarction: the British Heart Foundation RITA 3 randomised trial. Randomized Intervention Trial of unstable Angina. Lancet 2002, 360:743-751.

34. FIR Collaboration, Fox KA, Clayton TC, Damman P, Pocock SJ, de Winter RJ, Tijssen JG, Lagerqvist B, Wallentin L: Long-term outcome of a routine versus selective invasive strategy in patients with non-ST-segment elevation acute coronary syndrome a meta-analysis of individual patient data. J Am Coll Cardiol 2010, 55:2435-2445.

35. Boden WE, O'Rourke RA, Teo KK, Hartigan PM, Maron DJ, Kostuk WJ, Knudtson M, Dada M, Casperson P, Harris CL, Chaitman BR, Shaw L, Gosselin G, Nawaz S, Title LM, Gau G, Blaustein AS, Booth DC, Bates ER, Spertus JA, Berman DS, Mancini GB, Weintraub WS, COURAGE Trial Research Group: Optimal medical therapy with or without PCl for stable coronary disease. N Engl J Med 2007, 356:1503-1516.

36. Serruys PW, Kay IP, Disco C, Deshpande NV, de Feyter PJ: Periprocedural quantitative coronary angiography after Palmaz-Schatz stent implantation predicts the restenosis rate at six months: results of a meta-analysis of the BElgian NEtherlands Stent study (BENESTENT) I, BENESTENT II Pilot. BENESTENT II and MUSIC trials. Multicenter Ultrasound Stent In Coronaries. J Am Coll Cardiol 1999, 34:1067-1074.

37. Uchida T, Popma J, Stone GW, Ellis SG, Turco MA, Ormiston JA, Muramatsu T, Nakamura M, Nanto S, Yokoi H, Baim DS: The clinical impact of routine angiographic follow-up in randomized trials of drug-eluting stents: a critical assessment of "oculostenotic" reintervention in patients with intermediate lesions. JACC Cardiovasc Interv 2010, 3:403-411.

38. Topol EJ: Coronary angioplasty for acute myocardial infarction. Ann Intern Med 1988, 109:970-980.

39. Vaitkus PT, Brar C: N-acetylcysteine in the prevention of contrast-induced nephropathy: publication bias perpetuated by meta-analyses. Am Heart J 2007, 153:275-280.

40. Dawn AG, Balkrishnan R, Feldman SR: Systematic selection bias: a cause of dramatic errors in the inference of treatment effectiveness. J Dermatolog Treat 2008, 19:68-71.

41. Ioannidis JP: Meta-research: The art of getting it wrong. Res Syn Meth 2010, 1:169-184.

42. Roseman M, Milette K, Bero LA, Coyne JC, Lexchin J, Turner EH, Thombs BD: Reporting of conflicts of interest in meta-analyses of trials of pharmacological treatments. JAMA 2011, 305:1008-1017.

43. Moynihan R: It's time to rebuild the evidence base. BMJ 2011, 342:d3004

44. Jorgensen AW, Maric KL, Tendal B, Faurschou A, Gotzsche PC: Industrysupported meta-analyses compared with meta-analyses with non-profit or no support: differences in methodological quality and conclusions. BMC Med Res Methodol 2008, 8:60.

doi:10.1186/2046-4053-1-42

Cite this article as: Lodi-Junqueira et al:: Does intravascular ultrasound provide clinical benefits for percutaneous coronary intervention with bare-metal stent implantation? A meta-analysis of randomized controlled trials. Systematic Reviews 2012 1:42.

\section{Submit your next manuscript to BioMed Central and take full advantage of:}

- Convenient online submission

- Thorough peer review

- No space constraints or color figure charges

- Immediate publication on acceptance

- Inclusion in PubMed, CAS, Scopus and Google Scholar

- Research which is freely available for redistribution

Submit your manuscript at www.biomedcentral.com/submit
C Biomed Central 